\title{
Discussion on Fine Development of Vocational College Management
}

\author{
Bianling Zhang \\ School of Art and Design \\ Huanghe Science and Technology College \\ Zhengzhou, China
}

\begin{abstract}
This article introduces the theoretical connotation of fine management and its inspiration on management of colleges, and suggests that fine management is of consequence for newly-upgraded professional-level vocational colleges to break through the development bottleneck. In addition, it sets forth that fine management will be effective approaches and development directions of newly-upgraded professional-level vocational colleges and further comes up with strategies to implement fine management in such aspects as strategic planning, management mode, cultivation system of talents, and construction of campus culture etc.
\end{abstract}

Keywords-fine management; newly-upgraded professionallevel vocational colleges; development direction

\section{INTRODUCTION}

As the increasing popularization of higher education goes in our country, a part of secondary vocational schools are upgraded to professional-level higher vocational schools which, despite of preliminarily solving the extensive development issues such as increasing sources of students and enlarging teaching scale etc., still are confronted with problems on enhancing core competitiveness to realize sustainable development of colleges. Referring to years of experience on school running of developed and advanced colleges and successful experiences of other industries, this article suggests that conducting fine management is an effective method and development trend of boosting competitiveness of newlyupgraded professional-level vocational colleges.

\section{THEORETICAL CONNOTATION OF FINE MANAGEMENT AND ITS INSPIRATION ON MANAGEMENT OF COLLEGES}

The theory of fine management earliest appears in the enterprise management field and derives from the book Scientific Management written by J. P. Taylor in the beginning of 19th century and developed in lean production theory of Japanese Toyota Motor Corporation in 1950s. It is a management mode, and more an idea and culture. The "lean" refers to the key links and "fine" is the major control points of those key links characterized in the management mode of professionalization, systematization, standardization, routinization, datamation and informatization to enable each link to reach its optimal operation status so as to reduce costs and wastes and increase management efficiency in addition to guarantee product and service qualify for fulfilling more effects and strong competitiveness. Besides, fine management encourages people to break through conventional thinking and experience stereotype replaced by innovative thinking to realize continuous improvement and optimization on work processes and organizational systems.

The realization of fine management in social division of labor and qualify of services ushers in the wide application of the concept in diversified social fields. In 1990s, fine management extended its branches from enterprises to education domain and whereafter found broad application and research in education management. There were some scholars elaborated the significance of fine management to the connotative development of schools by introducing a successful example of Harbin University of Science and Technology who has achieved significant results by the application of fine management, and soon afterwards, scholars conducted discussion on the application of fine concept in college management for practicing it in university logistics management, talent cultivation system, vocational guidance, instructors' work and financial management etc.

Researches on fine management theory cast a great deal of enlightenment on the management of colleges and universities. First, it can prevent the occurrence of petrification and stereotype misunderstandings on management; fineness applying in enterprise and unit management requires strict accordance with procedures under definite division of labor and concrete responsibilities in addition to the requirements for focused, well-defined and precise work contents, which however, does not be regarded as stereotype or petrification. Different from enterprises, since schools are designed for teaching and have the special "product" - talents, its educational performance seems quite difficult to quantify, besides of far more complexity of teaching staff management than enterprise personnel management. Therefore, introducing fineness to school management should stick to people-oriented principle to fully arouse the maximum initiative and enthusiasm of teachers and students and realize the unification and harmony between standardized management and humanization care. Secondly, eliminate the misunderstanding on management to overstress trivial matters. Even if fine management attaches importance to detail management, it is far from being irrespective of the primary and secondary to be tangled in numerous and disorderly jobs; thus, introducing fineness to school management must avoid blind pursuit on 
"nuance" and "all matters" in case of complication of simple issues or neglect of the major events but tangled by trifles, which are definitely restricts to fine management. Moreover, fine management requires keen insights of managers for being capable of detecting the new changes of internal and external environments of schools and conducting management with innovative thoughts in addition to timely diagnosis on management implementation through evaluation mechanism and immediate improvement in case of any problems to continuously optimize every management link.

\section{FINE MANAGEMENT IS THE NECESSITY FOR NEWLY- UPGRADED PROFESSIONAL-LEVEL VOCATIONAL COLLEGES \\ TO BREAK THROUGH THE DEVELOPMENT BOTTLENECK}

The newly-upgraded professional-level vocational colleges occurring from the promotion of secondary technical schools, carry essentially management mode of schools and mode of thinking of people with natural defects not suitable for college development and during their transformation and development, those bottlenecks can only be broken through by the strengths of fine management.

Strategic planning and management mode: First, the strategic planning is lack of consciousness of innovation and disjointed from planning target. Influenced by closed schoolrunning pattern of technical secondary schools for a long time, school managers are not strongly aware of innovation and creativity and hardly consider the characteristic development and training of individualized talents during the strategic planning; even some schools just stay in the strategic planning stage and fail to analyze carefully benefits from input and output and other issues, resulting in objectives divorced distinctly from reality. Secondly, the current management mode adopted by schools acquires low efficiency and the connections among various departments are in shortage. The biggest difference between the management modes of technical secondary schools and junior colleges lie in: the former adopts vertical management; while the latter applies department (faculty) second-level flat management that requires unequivocal job functions, coordination of labor division and harmonious interaction between colleges and departments/faculties; hence, it appears particularly important to fulfill the determination and specification of management responsibility and realize active and efficient links of various departments. Besides, the traditional financial management experience and mode can no longer be fitted for school development which, for newly-upgraded professional-level vocational colleges, requires putting into amount of capitals for campus construction, and forces schools themselves to undertake the heavy responsibility for self-financing in a certain proportion under the pressure of limited funding and subsidy granted by the government. Obviously, the previous simple financial accounting system, basically substandard quality of personnel and apathetic awareness of managing expenditure and cost occurring during the period of technical secondary schools are no longer suitable for the current state of development under such a financial pressure.

Cultivation system of talents: as the society develops, the division of labor in all industries is increasingly elaborated and connected with other fields closer day by day. In addition, the social sustainable development tendency in our country requires more delicate cultivation quality of talents; take preschool education major as an example, besides of kindergartens, diversified preschool education emerging in the society including infant schools, early education institutions, parent-child organizations and other preschool service industries and cultural industries are related to preschool education major; on the other hand, Kindergarten Teachers' Professional Standards specifies 62 requirement details of kindergarten teachers' professional quality on the three aspects of professional concept and teacher's ethics, professional knowledge and professional competence, which requires newly-upgraded professional-level vocational colleges to realize delicate and efficient talent cultivation. With regard to professional building, those colleges generally incline to developing solid and characteristic majors equipped with abundant software and hardware facilities to dominant majors on the basis of which to extend relevant majors. The specific majors to be extended will be determined according to faculty, school-running conditions and actual demands of local areas in addition to sufficient scientific verification; nevertheless, some newly-upgraded professional-level vocational colleges are both deficient in data awareness and professional research analysts, which lets specialty investigation become formalistic and short of powerful data arguments to sound convincing during professional certification. Besides of absence of relevant professional teachers and academic leaders, schools also have poor performance in the strengths and results of talent introduction and cultivation, which obstacles the application for new majors submitted by schools to the superior administrative departments and further impacts on the overall progress of major construction.

\section{STRATEGY OF IMPLEMENTING FINE MANAGEMENT IN NEWLY-UPGRADED PROFESSIONAL-LEVEL VOCATIONAL COLLEGES}

Attach importance to strategic management and carry out fine public administration. A complete and effective strategic management system consists of three parts, strategic planning, strategy implementation, strategy assessment and control.

\section{A. Fineness of Strategic Planning}

(1) Achieve fineness when schools formulating strategic planning in which "fineness" requires, on the basis of strategic guiding thoughts and strategic targets, taking dominant majors and directions as the prior selections and putting collecting and planning of funds as the prominent position; furthermore "lean" mainly reflects in the analysis of advantage and disadvantage of schools, to lay stress on the collection of information and data that should be fully analyzed by scientific methods; in addition, it is necessary to define concrete strategic measures to guarantee the implementation of objects; what's more, the specific goals should be determined distinctly in various strategic stages according to the current state and objective tendency of future development. (2) Realize the fineness of public administration in strategy implementation. "Fineness" in implementing requires capturing the key link of "optimize allocation of resources and guarantee strategic emphasis"; moreover, "lean" is mainly embodied in, from the 
time, to disintegrate the planning targets and tasks for a medium and long term to an annual or semester objective; from the scope, to allocate the planning targets and tasks of school to each department/faulty to enable them to take their respective responsibilities in addition to facilitating and realizing through inspection and assessment; besides, to establish simplified and high-efficiency decision-making body for timely solving any problems occurring during the strategy implementation and driving its practice; and surrounding the core dominant major development, to set up special institutions and make appropriate adjustment and reinforce the coordination of the existing departments so as to realize resource sharing; to complete the corresponding systems and mechanisms to enhance executive force and ensure strategic planning to be implemented fully. Strategic evaluation refers to the process of evaluating the strategy implementation and taking necessary correcting measures and is a constantly circulatory feedback system. Due to complex and changeable external environment and constantly changing internal conditions, the strategic planning of schools should not be fixed and definite, but be under regular inspection on the implementing performance as every link of the plan. By frequently inspecting the performance of strategy implementation and referring to control standards to discover differences and analyze the causes, schools can take necessary correcting actions to fulfill high-efficiency management. (3) Accomplish the fineness of financial management in which "fineness" represents, by means of straightening out financial system, planning management level, defining responsibility and authorization and optimizing management etc., to improve the financial management level; on the other hand, "lean" mainly finds expression in: to set up the ideas of running school diligently and thriftily and building a conservationoriented campus by strictly prohibiting extravagance and waste, carefully calculating and strengthening management; and during the process of financial management, to widely collect information, refine the regulatory framework, specific management methods and operation rules \& procedures etc. of each link and level; moreover, to scientifically prepare budgets and raise the budget enforcement efficiency so as to continuously elevate the informationalized level of funds management.

\section{B. Fine Management of Talent Cultivation System}

(1) Achieve fineness when formulating objective of talent cultivation in which "fineness" requires not only major tastes and layers characteristics of objectives but embodying the local and school features and peculiarity; furthermore "lean" mainly reflects in: the talent cultivation objects vary to majors and are classified into primary goals, secondary goals, even third-level and fourth-level goals to eventually enable each detailed object including professional concept, professional knowledge and professional competence etc. of students to be measurable and visible. (2) Realize the fineness of talent cultivation mode. "fineness" in implementing talent cultivation mode requires capturing the "practicalness" trait of talent cultivation objectives of vocational colleges to determine an adaptable talent cultivation mode; moreover, "lean" is mainly embodied in: to bring forth new ideas of "school-enterprise combined" talent cultivation modes according to different majors and teaching orientations and to elaborately select eligible and competent cooperators in addition to further guaranteeing the practice and effectiveness of talent cultivation under clear and definite responsibilities and obligations through concluding a valid contract prior to any cooperation performed between schools and talent cultivation cooperative institutions. (3) Accomplish the fine construction of teaching system and its guarantee system. "fineness" in teaching system represents, surrounding the core task of making talent cultivation objectives come true, to focus on the core major construction of schools and ascertain the satisfying services of all guarantee systems; on the other hand, "lean" mainly finds expression in: while expounding and proving the talent cultivation schemes for diversified majors and orientations as well as the feasibility of course settings, to incarnate datamation and informatization, and to live up to harmony, close connection and inseparable supplementary relations among professional building, curriculum settings and teaching methods, as well as to strengthen the construction of practice base, teaching equipment, library resources and construction system of logistics hardware and teaching assessment. Furthermore, every link and task in the teaching guarantee system should be implemented by designate posts and it requires establishing scientific and standardized work processes under the responsibilities of specific persons.

\section{Fineness of Cultural Construction of New Campus}

"Fineness" in the cultural construction of campus refers to recognizing the significance of and laying emphasis on campus cultural construction by guaranteeing sufficient fund input to highlight the cultural characteristics of schools. "Lean" stands for, under the premise of coordination and unification, paying attention to details and conducting elaborate designs on every corner of campuses while programming the campus architectures to achieve humanization and particularity of every sculpture, every indicator and every catch-phrase; in addition, it is necessary to perfect system guarantee mechanism and establish \& improve the management system of new campuses to enable teaching and administrative staff to realize "everyone bears his share of the responsibility" for the cultural construction of new campuses, and to unify the understanding inwardly in addition to harmonize all departments for synchronizing steps and actions with united strength; moreover, it requires intensifying the communications between teachers and students and laying stress on frequently carrying out a full variety of positive campus cultural activities in new campuses.

\section{CONCLUSION}

Under the background of education reform, the managers of colleges and universities should draw lesson from foreign high-level fine management standards to set personnel training standards in their own schools. In order to promote the training of qualified personnel in Higher Vocational Colleges to meet the requirements of international standards, higher vocational schools should use modern science and technology methods to continuously update their own talents training mode. And in the evaluation of the teaching quality, higher vocational schools should complete the reform of teaching, and realize the 
evaluation criteria of teaching construction in many aspects so as to promote the higher vocational education in our country, improve the quality of education talents, and realize the development of education reform in our country. The implementation of fine management in higher occupation school is a key method to change the current situation of Higher Vocational Education in our country. To improve the quality of China's vocational education, get the actual teaching effect, and achieve a breakthrough in the development of higher occupation education, the following points should be done: spending more energy on the meticulous management teams, pursuing sophisticated talent management teams, building a senior research team, improving relevant management team, and having a high-level evaluation system.

\section{REFERENCES}

[1] Research on college logistics management from the Perspective of Fine Management, Master Thesis of Dalian University of Technology, May 2011.

[2] Niu Xizhen: Fine: Ideal and Pursuit of College Teaching Management, Journal of Southeast University (Philosophy and Social Science), Phase 11 of 2009.

[3] Wang Shuguo: Enhance School Connotative Construction by Applying Fine Management, China Higher Education, Phase 12 of 2007. 